\title{
La avalancha de Diego Muñoz: una novela que retrata la caída de la dictadura de Carlos Ibáñez*
}

\author{
La avalancha (the avalanche) by Diego Muñoz: a novel that \\ portrays the fall of the dictatorship of Carlos Ibáñez
}

Pablo Fuentes Retamal**

\section{RESUMEN}

Este artículo propone una lectura de la novela La avalancha (1932) de Diego Muñoz, a partir del estudio de las catálisis o pormenores narrativos, vale decir, aquellas unidades que articulan la diégesis a nivel político, simbólico e ideológico. De este modo, en detalles tan ínfimos como los colores que decoran el relato, las cabelleras de los personajes, la distribución del espacio novelesco, entre otros aspectos, se hallan indicios de un contexto histórico y social que subyace en los acontecimientos narrados.

\section{SUMMARY}

This article proposes a reading of the novel La avalancha (In English: The Avalanche) (1932) by Diego Muñoz, based on the study of catalysis or narrative details, that is, those units that articulate the diegesis at a political, symbolic and ideological level. In this way, in details as minute as the colors that decorate the story, the characters' hair, the distribution of the romantic space, among other aspects, there are indications of a historical and social context that underlies the events narrated.
Palabras clave:

Literatura chilena, Diego Muñoz, La avalancha, catálisis, dictadura de Carlos Ibáñez.

Keywords: Chilean literature, Diego Muñoz, La avalancha, catalysis, dictatorship of Carlos Ibáñez.

\footnotetext{
* $\quad$ Este artículo fue escrito en el marco del proyecto Fondecyt Posdoctoral 3170468: "Relatos que hablan desde el silencio. Eugenio González, Roberto Meza, Alberto Romero y Teófilo Cid ante la dictadura de Carlos Ibáñez del Campo". Investigador responsable Pablo Fuentes Retamal.

** Chileno. Doctor en Literatura Latinoamericana de la Universidad de Concepción. Académico de la Escuela de Educación, Universidad de Concepción, Campus Los Ángeles. Chile.pfuentesr@udec.cl
} 


\section{Presentación}

Tiranos inteligentes han caído en muchos países y en todos los tiempos. ¿Por qué nosotros no hemos de hacer caer a este imbécil que está en La Moneda?

Diego Muñoz, La AVAlancha (12).

La caída de la dictadura de Carlos Ibáñez (1927-1931) estuvo antecedida por la crisis económica de 1929. Esta recesión afectó con fuerza al mercado nacional, especialmente, a los sectores industriales que redujeron la mano de obra contratada en un tercio (Portales, Los mitos... 132). La depresión económica debilitó la alianza que la administración de Ibáñez había forjado con los sectores conservadores ${ }^{1}$, ruptura que aprovecharon las colectividades opositoras para favorecer un clima de agitación que contrarrestó el sello represivo que había impuesto la dictadura. El historiador Gonzalo Vial (1996) describe aquellas jornadas de protesta en el siguiente párrafo:

Santiago fue escenario de infinitos incidentes. En el segundo piso de los Tribunales, se desplegó un letrero contra Ibáñez ... alrededor del Palacio Judicial ... se multiplicaban los choques entre manifestantes y policías. ... Desde las ventanas de la casa perteneciente a Arturo Prat, ... dos nietos del héroe y otros muchachos hacían fuego de revolver sobre Carabineros ...

El comercio paralizó a las 12 horas, los bancos cerraron sus puertas. Los tranvías dejaron de correr. (545)

Estas manifestaciones se intensificaron, a causa del asesinato de Jaime Pinto Riesco ${ }^{2}$, estudiante de Medicina que fue baleado por un pelotón de Carabineros en las afueras del Hospital San Vicente (Vial 544). Esta fatalidad motivó la paralización de la asamblea médica y la adhesión de los facultativos a las jornadas de protesta (Teitelboim 190).

1 Luis Vitale (1992) indica que Carlos Ibáñez consiguió el apoyo de los sectores burgueses, vaticinando la llegada del comunismo a Chile. En este contexto, Ibáñez propuso la siguiente disyuntiva a sus adherentes: "esperamos con los brazos cruzados el advenimiento del Soviet o se organiza un Ministerio de orden político, enérgico y fuerte" (304). 2 Jaime Pinto Riesco tenía 24 años al momento de su muerte. Su madre era sobrina del presidente Riesco. Su padre era hijo del presidente Aníbal Pinto y nieto del presidente Francisco Antonio Pinto. Esta genealogía familiar permite que el historiador Gonzalo Vial señale que el joven asesinado "pertenecía al riñón de la vieja aristocracia chilena" (543). 
Una multitud, calculada en veinte mil personas, acompañó los restos del estudiante fallecido hasta el Cementerio General (Portales, Los mitos... 143). Esta aglomeración propició nuevas instancias de enfrentamientos con la policía, situación que culminó con la muerte del profesor Alberto Zañartu, docente herido por una bala que fue percutida por Carabineros. Esta tragedia intensificó las movilizaciones ciudadanas, de modo que "abogados, ingenieros, arquitectos, dentistas, farmacéuticos, personal de bancos, profesores medios y universitarios" (Vial 546) se sumaron a las manifestaciones de repudio contra la dictadura. El historiador Felipe Portales indica que la respuesta de Carlos Ibáñez ante este panorama fue acrecentar la represión, de modo que las calles de Santiago albergaron "una verdadera masacre" (143).

Analizar los factores implicados en la caída de la dictadura es una tarea que sobrepasa los límites de este artículo, no obstante, podemos señalar que la historiografía tradicional atribuye el derrocamiento de Ibáñez a la oligarquía, los segmentos profesionales y al estudiantado universitario (Vial 525; Charlín 382; Montero 152; Góngora 209). Otras perspectivas indican que los sectores populares propiciaron la caída de Ibáñez, por ejemplo, Volodia Teitelboim señala que "los estudiantes y los trabajadores ... cargaron sobre sus hombros el peso fundamental de la resistencia ... al dictador" (191). Clotario Blest añade que el régimen sucumbió ante "la fuerza del pueblo y no por un golpe militar" (cit. Echeverría 124). Olga Ulianova sugiere que "se trató de un movimiento espontáneo obrero-estudiantil ... para obtener la libertad de los pesos sociales .... La huelga general jugó un papel importante en la lucha" (98). Estimamos que la reflexión del historiador Luis Vitale es la más completa, pues reconoce la participación de todos los sectores implicados en la caída del régimen dictatorial:

El tirano fue derrocado el 26 de julio de 1931 por un frente político masivo pero heterogéneo. Este frente único contra la dictadura, compuesto por la mayoría de las fracciones burguesas, capas medias y sectores obreros ... abrirá un periodo de inestabilidad. (313)

La literatura chilena se preocupó de registrar los movimientos ciudadanos y las jornadas de protestas que resistieron al régimen ibañista. El escritor Diego Muñoz (1903-1990) pormenorizó los últimos días de la dictadura en La avalancha (1932), novela de carácter testimonial, escrita pocos "días después de los sucesos que condujeron a la caída de 
la dictadura, en julio de 1931" (Neruda, “Carbón..." 9). El poeta Neruda describe el argumento de este relato en el siguiente fragmento:

La avalancha, testimonio directo de quien vivió hora por hora aquellos sucesos, reportaje vivo de la lucha que se desarrolló de día y de noche, hasta la victoria clamorosa. Por las páginas de esa novela huyen o acometen las multitudes y los individuos cuya rebeldía se desata ... para quedar como advertencia histórica. El realismo, la objetividad de este libro ansiosamente escrito y publicado, han hecho que se lo señale, aquí y en otros países de América, como documento de aquellos cinco días de conmoción. (9-10)

Desafortunadamente, La avalancha tuvo un escaso tiraje, pues, este relato se publicó a inicios de 1932, vale decir, a meses de haber caído el régimen de Ibáñez, época en que aún se mantenían vigentes algunos agentes de la dictadura. Estas contrariedades dificultaron la circulación de la novela, de modo que sus páginas no pudieron ser consultadas con el interés y la profundidad que merecen. Por consiguiente, el propósito que acoge este artículo es estudiar La avalancha para averiguar cuáles son los recursos estilísticos que privilegió su narrador para describir la violencia política y social que aconteció en los últimos días de la dictadura.

Estimamos provechoso estudiar los recursos estilísticos elegidos por el narrador de La avalancha, pues en el discurso testimonial los elementos estructurales capturan la esencia de una experiencia traumática del pasado, fijándola, mediante el discurso, en la memoria (Sarlo 55).

Nuestra hipótesis de trabajo sugiere que los elementos mínimos del relato, vale decir, aquellas unidades que Roland Barthes (1987) denominó "catálisis", articulan los valores temáticos, simbólicos e ideológicos que sostienen la narración. Recordemos que Roland Barthes distingue en "El efecto de realidad" dos unidades narrativas: las denominadas "funciones cardinales" que constituyen las bisagras del relato y las llamadas "catálisis" que completan los espacios vacíos entre aquellas primeras funciones (179). A simple vista, podríamos pensar que las catálisis no son más que detalles, en apariencia inútiles, que solo elevan el coste de la información narrativa, sin embargo, estas anotaciones son de gran relevancia, pues otorgan verosimilitud a la 
narración. Barthes cita un fragmento de Un corazón sencillo (1877) de Gustave Flaubert para demostrar la preponderancia de las catálisis, puntualmente, refiere aquel pasaje del relato que describe la sala de madame Aubain: "Un pequeño vestíbulo separaba la cocina de la sala donde ... se pasaba el día entero, sentada junto a la ventana en un sillón de paja .... Un piano viejo soportaba, bajo un barómetro, una pirámide de cajas y cartones" (cit. en Barthes 186). Aquel piano, barómetro, cajas y cartones no cumplen otra función más que señalar: "nosotros somos lo real" (Barthes 186). En síntesis, aquellos "detalles en apariencia inútiles" son aspectos de máxima consideración para el relato, pues aportan unidades de verosimilitud que denotan directamente lo real.

El segundo pilar teórico que orienta nuestra lectura crítica corresponde a la reflexión de Michel Foucault en Vigilar y castigar (2002 ). Este filósofo indica que "la mecánica del poder" concibe en los pormenores una acumulación de procesos minúsculos que convergen en beneficio de un diseño mayor (136). Por consiguiente, describir una microfísica implica prestar atención a detalles y minucias que, mediante un funcionamiento coherente y organizado, aportan sentido a lo ínfimo e insignificante.

La reflexión teórica de Hayden White también ilumina nuestra lectura crítica. Este filósofo revitalizó la conceptualización del discurso historiográfico al sugerir que una misma secuencia de hechos se puede "tramar"3 desde diferentes perspectivas. De este modo, la narración histórica es el resultado de la sutileza del historiador al momento de privilegiar una "trama específica" para aquellos acontecimientos a los que se adjudica "un tiempo especial de significado" ("El texto histórico..." 115). A partir de esta conceptualización, White establece vínculos profundos entre historia y literatura para evidenciar la base lingüística sobre la que se articula toda obra histórica (Metahistoria... 10); en otras palabras, lo que sugiere este filósofo es que,

Ningún conjunto dado de acontecimientos históricos casualmente registrados puede por sí mismo construir un relato .... Los acontecimientos son incorporados en un relato mediante la supresión y subordinación de algunos de ellos y el énfasis en otros, la caracterización, la repetición de motivos, la variación del tipo y el punto de

3 Según Hayden White, "trama" es la manera en que una "secuencia de sucesos organizados se revela de forma gradual como un relato de cierto tipo particular" (Metahistoria 17). 
vista, las estrategias descriptivas alternativas y similares; en suma, mediante todas las técnicas que normalmente esperaríamos encontrar en el tramado de una novela. (113)

De esta manera, los acontecimientos descritos en un relato histórico no cambian, sustancialmente, de un texto a otro; lo que difiere son las "modalidades y las relaciones que el historiador establece entre estos sucesos" (Metahistoria 134). En términos sencillos, lo que Hayden White pretende demostrar es que "hay un elemento de historia en toda poesía, y también un elemento de poesía en cada relato histórico" ("El texto histórico..." 136).

El valor de lectura crítica que proponemos en este artículo se incrementa luego de revisar la bibliografía precedente y constatar que solo dos reseñas han referido algunas particularidades de La avalancha. En primer orden, Raúl Silva Castro destacó en Panorama de la novela chilena (1955) el ritmo y la fluidez con que el narrador pormenoriza las acciones narrativas, en este sentido propone que La avalancha es un relato "nervioso que describe con fidelidad encomiable el ambiente callejero a la caída de Ibáñez" (211). Por su parte, Claudio Solar indica que la novela de Diego Muñoz describe la madurez de un movimiento social que devino "una avalancha para exigir la cabeza del gobernante" (4).

Estimamos que la lectura crítica que propone este trabajo será un aporte significativo a los estudios literarios chilenos, pues no tenemos noticias de otro estudio que analice La avalancha. También consideramos importante destacar que nuestra reflexión rescata la capacidad de la literatura para revisitar el pasado y hallar pasajes de vida, incluso allí, donde se desplegaron procesos de deshumanización.

\section{La avalancha: un relato de los últimos días de la dictadura de Ibáñez}

Era preciso unirse, como único medio eficaz para derrocar al tirano.

Diego MuÑoz, LA AVALANCHA (22).

Las primeras páginas de La avalancha pormenorizan los enfrentamientos que sostienen un grupo de estudiantes universitarios con un pelotón de carabineros: 
Cuatro carabineros, blandiendo sus bastones blancos, dispersaban a los transeúntes detenidos cerca de la Universidad de Chile.

Los bastones blancos sonaban sordamente sobre los cuerpos. En breves segundos la multitud se dispersó ante el ataque fiero de los uniformes verdes.

Un violento garrotazo cayó sobre una cabeza. Veinte voces hubieran querido gritar una grosería, pero callaron cobardemente.

Otro [carabinero] conservaba la mitad de su bastón, que se había quebrado en la refriega. (3-5)

Es curioso que el narrador haya decidido pintar de color "blanco" los bastones de carabineros, pues el equipamiento policial, de aquel entonces, se componía de una luma de "meli", árbol cuya madera es rojiza y de gran dureza (Hall y Witte 36). Por consiguiente, el color blanco de los bastones responde a una decisión estética del narrador cuyo propósito es destacar los rastros de sangre de los manifestantes sobre las armas policiales, una estrategia descriptiva que evidencia la desmesura del actuar policial.

En medio de esta violencia exacerbada, el narrador retrata la irritación ciudadana ante los excesos policiales mediante el siguiente arreglo descriptivo: vincula la presencia policial con las heces que dejan las caballerizas institucionales tras su paso. A modo de ejemplo, para evidenciar cómo opera este arreglo descriptivo en el relato, citamos un par de referencias textuales: "minutos más tarde llegaron Carabineros de caballería .... El olor a estiércol empezó a invadir aquella parte de la avenida" (6). Algunas páginas más adelante, el narrador reitera este recurso estético: "las fuerzas de gobierno llegaban a la Alameda ... uno de los caballos dejó frente a la casa de los estudiantes la huella de su paso" (30).

La reiteración de este procedimiento descriptivo nos remite a la reflexión de Luz Pimentel (2001), quien indica que toda asociación "lexema-tema" conlleva la articulación de un microuniverso semántico cuyos elementos descriptivos forjan una relación de "contigüidades obligadas" (59). Esta redundancia sémica es un recurso descriptivo que 
ofrece "una base clasemática jerarquizada" que otorga uniformidad al discurso narrativo, de modo que los lectores reconozcan un mismo patrón semántico a lo largo de todas las páginas del relato (Pimentel 73).

Remitiéndonos a nuestro marco teórico, indicamos que la violencia descrita en La avalancha conlleva implicancias históricas, perspectiva de análisis que nos facilita la reflexión de Hayden White. Esta teorización sugiere que el relato literario posee las competencias necesarias para convocar aquellos contenidos históricos que el narrador pretende visibilizar en la diégesis, en este sentido, la novela de Muñoz pormenoriza los excesos policiales con el propósito de explicar cómo la violencia descomedida justifica - en cierta medida- el alzamiento popular. El historiador Felipe Portales se refiere a los abusos cometidos por el cuerpo de Carabineros en el siguiente fragmento:

[La dictadura de Ibáñez] no experimentó manifestaciones masivas en su contra, salvo en su desenlace final. Fue, precisamente, durante la represión callejera de los últimos días de la dictadura que se empleó una violencia homicida por parte de la policía que, según un informe presentado a la Cámara por el diputado radical Arturo Lois, se convirtió en una verdadera masacre. (Los mitos... 89)

La investigación historiográfica indica que el descontento popular se tradujo en incidentes callejeros que culminaron con "la huelga indefinida y la toma de la Universidad de Chile" (Portales, Los mitos... 141). El narrador de La avalancha acoge estos antecedentes históricos y los incorpora al relato, puntualmente, a aquel pasaje de la narración que describe lo siguiente: "solo una proposición fue aceptada con firmeza unánime: la Universidad [de Chile] quedaría en poder de los estudiantes, y no la entregarían mientras no hubiese autoridades aceptadas por todos" (21).

Los diálogos que mantienen los personajes en esta sección del relato son provechosos para nuestra lectura crítica, pues estos comentarios contextualizan los métodos represivos que dispuso la dictadura de Ibáñez para sofocar todo intento de insurrección. De esta manera, gracias a la conversación que mantiene Carlos Donoso con una manifestante, nos enteramos del viaje que emprendió este personaje al extranjero para finalizar sus estudios de abogacía: "aquellas ... narraciones del Ecuador habían despertado en ella la curiosidad" (11). Un 
lector poco informado podría pensar, equivocadamente, que este diálogo es irrelevante en el argumento de La avalancha, una conversación cuyo propósito es matizar una escena colmada de discusiones políticas; por el contrario, cuando el narrador menciona la estadía de Carlos Donoso en Ecuador, está revelando una de las estrategias de represión que dispuso la dictadura para silenciar a los estudiantes rebeldes que contradijeron sus mandatos, pues el poder ordenó cancelar las matrículas universitarias de estos jóvenes y rechazar cualquier instancia de reincorporación a su casa de estudios.

Entre los estudiantes universitarios que padecieron esta injustica se encuentra el propio escritor Diego Muñoz, quien fue expulsado de la Facultad de Derecho de la Universidad de Chile, a causa de su disidencia (Lagos 2). El escritor, junto con una decena de compañeros, no tuvo más opción que trasladarse hasta Ecuador para continuar sus estudios jurídicos. Arturo Olavarría Bravo (1962), uno de los estudiantes exonerados, describe el periplo que realizó este grupo de jóvenes para continuar con sus estudios en la Universidad de Quito:

Partimos de Santiago, de la Estación Mapocho, el 6 de septiembre de 1927. El grupo de viajeros, todos expulsados de la Universidad .... Embarcados el día 7 de septiembre en el vapor "Bologna", partimos con rumbo a Ecuador.

He rendido hoy (12 de noviembre de 1927) mi examen de incorporación a la Corte Suprema de Ecuador, como aquí se le denomina, y que en Chile se llama simplemente examen de abogado ... Soy, pues, abogado, cumpliendo de este modo la gran aspiración de mi vida. (206)

Siguiendo los planteamientos teóricos de Hayden White, identificamos otra anotación en La avalancha que posibilita el diálogo entre literatura e historia. Nos referimos a aquella escena de la novela que presenta un conversatorio entre estudiantes, a propósito de las consecuencias que implicaría radicalizar las manifestaciones: "Esta vez no te llevarían a Más Afuera ${ }^{4}$ : te fondearían, como lo hicieron con otros (disidentes)" (11).

$4 \quad$ La cursiva es nuestra. 
Para comprender las implicancias del nombre propio, "Más Afuera", es necesario revisar algunas investigaciones históricas acerca de esta isla ubicada en el archipiélago de Juan Fernández, cuyo nombre no se registra en los documentos cartográficos actuales ${ }^{5}$. El historiador Jorge Flores (1993) indica que el sello represivo del régimen dictatorial de Ibáñez estuvo dado por las detenciones, relegaciones y exilios, de modo que el hostigamiento político fue una amenaza constante que no se limitó a momentos de agitación (23). Esta persecución política facilitó la aprehensión de un millar de personas que fueron desplazadas a prisiones políticas erguidas a lo largo de todo el país ${ }^{6}$, mientras que a los ideólogos de la oposición se les encarceló en colonias penitenciarias ${ }^{7}$ dispuestas para estos fines. En este punto adquiere relevancia “Más Afuera", isla-prisión que albergó el centro de reclusión política más inhóspita y cruel de todo el régimen (Flores 40). El abogado Carlos Vicuña (2002) describe las condiciones extremas que soportaron los prisioneros políticos en esta colonia penitenciaria:

Más Afuera es una isla baja lluviosa, perdida en el océano, a 600 millas de Valparaíso. Pertenece al grupo de Juan Fernández. Su clima es fuerte, casi tropical, pues queda más allá de la corriente de Humboldt, y su escaso relieve la hace víctima de los vientos del océano ... En Más Afuera nada ha podido prosperar, salvo las cabras ... Están [los pabellones que albergan a los prisioneros] a la orilla del mar, encima de rocas de difícil acceso, porque en toda la isla no hay puerto alguno, ni bahía, ni caleta ... Allí permaneció el primer grupo de perseguidos políticos un año y medio: ningún delito tenía, no fueron procesados ni interrogados. (352)

La colonia penitenciaria Más Afuera albergó a "ciento cuarenta confinados políticos" (Vicuña 352), en su mayoría, militantes anar-

5 Blanca Luz Brum, escritora y pintora uruguaya, residente en Más Afuera, inició una campaña para renombrar la isla. El presidente Eduardo Frei Montalva acogió esta petición en 1966, desde entonces, Más Afuera se nomina "Alejandro Selkirk" en honor al marinero escocés que fue abandonado en este lugar.

6 Las ciudades que cobijaron prisiones políticas fueron: Valparaíso, Concepción, Santiago, Rancagua, Arica, Copiapó, Limache, San Felipe, Puerto Montt y Constitución (Flores 24).

7 El Reglamento de prisiones que promulgó la administración de Ibáñez, en mayo de 1928, dispone lo siguiente en el Artículo 102: "Se establecerán colonias penales en el territorio de Aysén y en la isla Más Afuera, las que tendrán el personal que se fije anualmente en la Ley de presupuestos y la dotación que se consulte al cuerpo de Gendarmería" (León 464). 
quistas y comunistas de origen obrero (Flores 34). De este modo, consideramos que el narrador de La avalancha menciona que uno de sus personajes, Carlos Donoso, estuvo desterrado en "Más Afuera" con dos propósitos: en primer lugar, para referir las atrocidades que cometió el poder contra sus opositores y, en segundo orden, para reconocer la rebeldía del personaje que lidera las manifestaciones de rechazo a la dictadura en la ficción novelesca. Estos antecedentes demuestran que Hayden White está en lo correcto al sostener que el novelista, al igual que el historiador, posee las competencias necesarias para visibilizar ciertos acontecimientos en el texto literario (“El texto histórico..." 112).

Las descripciones de los manifestantes que propone el narrador son provechosas para nuestra lectura crítica, ya que estas pormenorizaciones convergen en un mismo detalle: el alborotamiento del pelo y de los bigotes de los personajes. Para demostrar cómo operan estas catálisis en la narración citamos un fragmento que describe la apariencia de una estudiante:

- ¿Quién es, quién es? preguntaron sucesivamente los oyentes....

-Eva Fernández, del Pedagógico. La muchacha, con los cabellos revueltos y una mirada fiera. (23)

También referimos un fragmento que describe los mostachos de un carpintero que discute en la asamblea: "El viejo se puso más pálido aún, se pasó varias veces una mano por sus bigotes indomables" (52).

Estimamos que el narrador de La avalancha emplea los detalles mínimos del relato, vale decir, el cabello alborotado y los bigotes indómitos, para reforzar la rebeldía de sus personajes. Este recurso descriptivo comprueba que Barthes está en lo correcto al sostener que las catálisis otorgan verosimilitud a la narración, y, además, evidencian que los pormenores narrativos, mediante un funcionamiento coherente y organizado, aportan sentido a lo ínfimo e insignificante (Foucault 136). En este sentido, es prudente mencionar otro pasaje de La avalancha que describe la cabellera "roja" de un muchacho que discute en la asamblea estudiantil:

— ¿Qué hay de nuevo? - preguntó el recién llegado.

- Habla tú, que vienes de afuera - dijo un estudiante de pelo rojo.

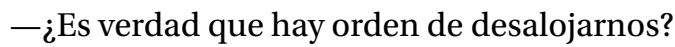


-Mentira. Donoso sabía que eso era verdad, pero más valía no decirlo. (37)

Colorear con "rojo" la cabellera de aquel estudiante es un recurso estilístico que sobrepasa el simple propósito de "pintar" una sección del relato, pues esta elección cromática se articula, a partir de los significados ideológicos que sostienen la narración. Para profundizar en este aspecto remitimos la teorización de Phillipe Hamon, quien indica que los "componentes tonales" son un centro de imantación de los valores ideológicos que articulan el relato (cit. Pimentel 28). De este modo, cuando el narrador de La avalancha pinta de "rojo" la cabellera de un personaje, está sugiriendo una lectura política de este matiz, en otras palabras, se escoge una tonalidad que remite a los Partidos Socialistas y Laboristas, organizaciones políticas que escogieron el color rojo para representar la Segunda Internacional, simbolizar la Unión de Repúblicas Socialistas Soviéticas y las banderas de los Partidos Comunistas del mundo. En este contexto, Pablo Soler añade que el rojo es "el color de la rebelión" (26).

El color rojo es un pormenor narrativo cuyas implicancias incumben a los manifestantes y a los agentes del régimen dictatorial. Recordemos que Carlos Ibáñez promulgó un decreto que prohibió exhibir todo símbolo que promoviera la desobediencia, especialmente, la "bandera roja":

Desde hoy, en consecuencia, no habrá en Chile ni comunismo ni anarquismo. El control del país no pueden tenerlo ... desplazados de la cosa pública, como no lo tendrán tampoco los que han tenido la audacia de reemplazar nuestra bandera por el trapo rojo. (cit. en Flores 24)

Este mandato encuentra un correlato en La avalancha, puntualmente, en aquel episodio que describe los esfuerzos de un escuadrón de Carabineros por arriar una bandera con letras rojas que permanece izada en uno de los balcones de la Universidad de Chile: "una bandera (...) decía LIBERTAD ${ }^{8}$ en letras rojas como sangre" (28). En medio de esta escena, un pelotón policial arremete en la casa de estudios para descolgar el estandarte rojo:

8 El texto original utiliza mayúsculas para destacar la palabra "Libertad". 
Un pelotón de carabineros de infantería avanzó ... hacia la Universidad.

La puerta principal se abrió. Los carabineros entraron por ella.

Momentos más tarde desapareció la bandera blanca en que se había escrito LIBERTAD con letras rojas. (98-9)

El modo en que procede la policía nos demuestra que Michel Foucault está en lo correcto al señalar que el poder hace presa en "detalles" para otorgar sentido a lo ínfimo e insignificante (136). Efectivamente, un detalle en apariencia irrelevante, como es el color de una bandera, es un antecedente suficiente para evidenciar las estrategias de control que dispuso la dictadura ibañista para sofocar todo intento de rebelión.

El narrador de La avalancha distribuye el espacio diegético según la filiación política a la que adscriben sus personajes. De acuerdo con este criterio, los disidentes se ubican en el ala izquierda del relato, mientras que los agentes de la dictadura habitan en el flanco derecho de la novela. Para comprobar esta distribución espacial citamos un pasaje del relato que ubica a los manifestantes en el sector izquierdo del relato:

Un grupo de obreros acompañó algunas cuadras a Donoso, Romo y el tipógrafo ... Poco a poco fueron apartándose los acompañantes; por fin, los tres amigos continuaron solos su camino. Ya estaban cerca, en la próxima esquina doblarían hacia la izquierda. (14)

A su vez, la casa del coronel Vargas, funcionario policial que comanda el escuadrón encargado de reprimir las manifestaciones, se ubica en el costado derecho del relato: "Aquella pieza era el salón de la casa, a la derecha, una ampliación antigua del coronel Vargas, cuando era capitán" (50-1). En el margen derecho de la vivienda del coronel Vargas hallamos la habitación del agente Urrutia: "en la casa vecina ... hacia la derecha ... se abrió una puerta y salió un hombre apresuradamente. Debía ser el agente Urrutia, de la Sección de Seguridad, que vivía allí con su mujer" (16).

La distribución del espacio diegético que sugiere el narrador nos remite a la reflexión de Michel Foucault, ciertamente, los pormenores del relato adquieren sentido mediante un funcionamiento coherente y orga- 
nizado (136). Este principio teórico explica porqué los personajes rebeldes de La avalancha - estudiantes, comunistas, proletarios, y anarquistas- habitan en el ala izquierda del espacio diegético, mientras que sus contrarios - los partidarios de la dictadura de Ibáñez- se ubican en el flaco derecho del relato. Esta distribución espacial es una estrategia estilística que dispuso el narrador para que sus lectores distingan, sin ningún inconveniente, los bandos políticos que se describen en la novela.

Estimamos provechoso atender los sectores del espacio diegético que ilumina el narrador en esta sección del relato, ya que esta mirada aporta elementos significativos para nuestra lectura crítica. Mientras que la casa del coronel Vargas se ilumina por motivos festivos: "Había luz en la casa del coronel ... alguien tocaba adentro un alegre fox-trot" (64); a su vez, la habitación de un obrero disidente hace lo propio, pero por motivos fúnebres, pues la hija menor de este trabajador perdió la vida durante las arremetidas que perpetraron las caballerizas policiales en las manifestaciones:

Frente a la casa del carabinero, velaban el cadáver de Laurita. En el mismo dormitorio que ocupaba el zapatero y su mujer, allí mismo velaban ahora a la niña ... Cuatro velas encendidas esquinaban el humilde ataúd; aparte de esa luz, no había otra que la del compartimiento donde se hallaba la mesa del zapatero; una vieja lámpara de petróleo. (66)

El narrador de La avalancha describe en los capítulos finales de la novela cómo se recrudece la violencia policial. En este contexto, dos personajes mantienen el siguiente diálogo:

- La cosa está tremenda en el centro- dijo "el Lucho" mientras caminaban.

$-i$ Hay balas?

-Todavía no.

—Entonces no es nada- dijo el ronco Núñez. - Yo me encontré en el norte en la matanza de San Gregorio ${ }^{9}$. iAhi sí que fue grande! (55)

A primera vista, podríamos pensar que el fragmento citado no aporta nuevos antecedentes a esta investigación, pero si agudizamos la mirada,

$9 \quad$ La cursiva es nuestra. 
notaremos que la mención a la "matanza de San Gregorio" es una estrategia discursiva que visibiliza algunos antecedentes de esta tragedia obrera. Recordemos que esta matanza ocurrió en una oficina salitrera cercana a Antofagasta, en febrero de 1921, en el marco de la grave crisis económica que afectó a la industria minera. Entonces, las compañías salitreras desvincularon a sus empleados sin otorgar ningún tipo de desahucio, lo que provocó que una multitud de cesantes se agolpara en las oficinas de la Casa Gibss (propietaria de las compañías mineras) para exigir el pago de las indemnizaciones correspondientes. La multitud encaró a Daniel Jones, administrador de la compañía, y a un grupo de soldados que custodiaba el lugar comandado por el teniente Buenaventura Argandoña. El pelotón militar ordenó a la muchedumbre dispersarse pero, tras advertir que sus órdenes no eran obedecidas, los efectivos de Ejército procedieron a percutir sus armas, asesinando a un grupo de setenta a ochenta trabajadores. Como resultado de esta matanza, el administrador Jones y el teniente Argandoña fueron ajusticiados por la multitud (Portales, Historias desconocidas... 36).

Desde la mirada que propicia nuestro marco teórico, proponemos que la mención a la "Matanza de San Gregorio" es una estrategia discursiva que permite al narrador visibilizar los contenidos históricos que permanecen soterrados en el texto literario. En este sentido, las unidades mínimas del relato constituyen referentes lingüísticos que trazan puentes efectivos entre el universo textual y el extratexto, ofreciendo a la diégesis la posibilidad de entablar relaciones significativas con el discurso histórico (White).

Las páginas finales de La avalancha describen la caída del régimen dictatorial de Carlos Ibáñez: “a mediodía, como una explosión que fue repitiéndose en cada calle, saltó la noticia que todos esperaban: Ibáñez había renunciado" (113). Estas escenas están colmadas de alegría, situación que no habíamos conocido en los capítulos anteriores de esta novela cuyos párrafos solo describían enfrentamientos y desmesura policial: "repartiendo a gritos el triunfo, hombres desconocidos entre sí se abrazaban con júbilo en las calles" (113). Estimamos necesario destacar las palabras de fraternidad con que finaliza La avalancha, un mensaje que promueve instancias de encuentro entre aquellos compatriotas que permanecieron enemistados, a causa de diferencias políticas: “así terminó el último día para los que habitábamos en una 
misma cuadra de la ciudad" (122). El narrador dirige esta referencia textual al coronel Vargas y al zapatero que perdió a su hija durante los enfrentamientos, personajes que comparten un mismo barrio pero que se mantenían enemistados, a propósito de sus diferencias políticas. Una vez que concluye la dictadura de Ibáñez, las enemistades se diluyen y se renuevan las promesas de fraternidad.

\section{Palabras finales y proyecciones}

Había que terminar con la dictadura; era preciso organizarse, ponerse en contacto con los estudiantes, salir de la indiferencia.

Diego MuÑoz, La AVALANCHa (12).

La discusión propuesta en este artículo demuestra que el narrador de La avalancha pormenoriza los sucesos que acontecieron en los últimos días de la dictadura de Ibáñez mediante las "catálisis" o detalles de la narración. Estas unidades mínimas convocan los valores discursivos e ideológicos que articulan el relato, una estrategia descriptiva que traza un puente efectivo entre el universo diegético y el extratexto.

Los pormenores narrativos también precisan la contingencia histórica de la época. En este sentido, el narrador incorpora a su relato lugares (Más Afuera) y acontecimientos (la matanza de San Gregorio) que evocan los fundamentos históricos que sostienen la narración. Este procedimiento estilístico evidencia que la labor del novelista es similar a la tarea del historiador, pues ambas actividades seleccionan "tramas discursivas" afines a la "verdad" que se pretende contar (White).

Si tuviésemos que evaluar la novela de Diego Muñoz en cuanto a su capacidad para reflejar especularmente la realidad, tendríamos que precisar que este relato adolece de un problema: atiende, excesivamente, a los sectores proletarios, restando protagonismo a los segmentos profesionales que también incidieron en la caída de la dictadura. Este sesgo se justifica al considerar la militancia comunista de Diego Muñoz, filiación política que parece conspirar en contra de la labor narrativa del autor, ya que su prosa no expresa todo su potencial a causa de estos "valores doctrinarios" (Orellana 116).

Consideramos interesante extender los parámetros de reflexión que hemos propuesto en este artículo a otros relatos de Diego Muñoz, 
especialmente, a su novela De repente (1933), relato que el poeta Pablo Neruda estima uno de "los libros más fascinantes de nuestra literatura" ("De Pablo Neruda para..." 5). También sería provechoso establecer diálogos intertextuales entre la obra narrativa de Diego Muñoz y la producción literaria de otros autores afines a este proyecto escritural, por ejemplo, Luis Enrique Délano y su novela La base (1958), relato que describe la insurrección popular que aconteció a fines del segundo gobierno de Carlos Ibáñez (1952-1958), una prosa que destaca las estrategias que diseñaron los circuitos rebeldes de aquella época para resistir los embates del poder.

\section{Referencias bibliográficas}

Barthes, Roland. "El efecto de realidad". El susurro del lenguaje. Más allá de la palabra y la escritura. Madrid, Paidós, 1987, pp. 179-187. Impreso.

Charlín, Carlos. Del avión rojo a la república socialista. Santiago de Chile, Quimantú, 1972. Impreso.

Echeverría, Mónica. Antihistoria de un luchador. (Clotario Blest 18231990). Santiago de Chile, Lom ediciones, 1993. Impreso.

Flores, Jorge. La dictadura de Ibáñez y los sindicatos (1927-1931). Santiago de Chile, Dirección de Bibliotecas, Archivos y Museos, 1993. Impreso.

Foucault, Michel. Vigilar y castigar. Nacimiento de la prisión. Buenos Aires, Siglo XXI, 2002. Impreso.

Góngora, Mario. Ensayo histórico sobre la noción de Estado en Chile en los siglos XIX y XX. Santiago de Chile, Editorial Universitaria, 2006. Impreso.

Hall, Michael y Witte Jörg. Maderas del sur de Chile. Árboles, aplicaciones y procesos. Santiago de Chile, Editorial Universitaria, 2004. Impreso.

Lagos, Marino. "El escritor Diego Muñoz". La prensa Austral [Punta Arenas, Chile]. 17 May. 1990, p. 2. Impreso.

León, Marco. "Documento para la historia de las prisiones en Chile en el siglo XX (1911-1965)". Revista Chilena de Historia del Derecho, no. 20, 2008, pp. 371-631.

Montero, René. La verdad sobre Ibáñez. Santiago de Chile, Zig-zag, 1952. Impreso. 
Muñoz, Diego. La avalancha. Santiago de Chile, Recurba, 1932. Impreso.

Neruda, Pablo. "Carbón". Carbón. Santiago de Chile, Editora austral, 1953, pp. 7-12. Impreso.

"De Pablo Neruda para esta edición Saluuuuuud!... a Diego Muñoz". De repente. Santiago de Chile, Tajamar editores, 2011, pp. 5-7. Impreso.

Olavarría, Arturo. Chile entre dos Alessandri. Memorias políticas. Tomo I. Santiago de Chile, Nascimiento, 1962. Impreso.

Orellana, Carlos. Informe final. Las memorias de un editor. Santiago de Chile, Catalonia, 2008. Impreso.

Pimentel, Luz. El espacio en la ficción. Buenos Aires, Siglo XXI, 2001. Impreso.

Portales, Felipe. Los mitos de la democracia chilena. Desde 1925 a 1938. Volumen II. Santiago de Chile, Catalonia, 2006. Impreso. Historias desconocidas de Chile 2. Santiago de Chile, Catalonia, 2018. Impreso.

Sarlo, Beatriz. Tiempo pasado. Cultura de la memoria y giro subjetivo. Una discusión. Talca, Universidad de Talca, 2003. Impreso.

Silva Castro, Raúl. Panorama de la novela chilena. México, D. F., Fondo de Cultura Económica, 1955. Impreso.

Solar, Claudio. "La avalancha". La Estrella de Valparaíso [Valparaíso, Chile]. 2 Feb. 1968, p. 4. Impreso.

Soler, Pablo. El enigma de los símbolos. México, D. F., Fondo de Cultura Económica, 2013. Impreso.

Teitelboim, Volodia. Antes del olvido. Un muchacho del siglo veinte. Santiago de Chile, Sudamericana, 1998. Impreso.

Vial, Gonzalo. Historia de Chile (1891-1973). La dictadura de Ibáñez (1925-1931). Volumen IV. Santiago de Chile, Editorial Fundación, 1996. Impreso.

Vicuña, Carlos. La tiranía en Chile. Libro escrito en el destierro en 1928. Santiago de Chile, Lom ediciones, 2002. Impreso.

Vitale, Luis. Interpretación marxista de la historia de Chile. De la República Parlamentaria a la República Socialista (1891-1932). Tomo V. Santiago de Chile, Lom ediciones, 1992. Impreso.

Ulianova, Olga. "El Partido Comunista chileno en la crisis política de 1931: de la caída de Ibáñez al levantamiento de la marinería". Bicentenario, no. 3, 2004, pp. 63-102. 
White, Hayden. Metahistoria. La imaginación histórica en la Europa del siglo XIX. México, D. F., Fondo de Cultura Económica, 1992. Impreso.

. "El texto histórico como artefacto literario y otros escritos". El texto histórico como artefacto literario. Barcelona, Paidós, 2003, pp. 107-139. Impreso. 